\title{
Neuro-Behçet's Disease Presenting as Hypertrophic Pachymeningitis
}

\author{
Byung-Nam Yoon ${ }^{1}$, Soo-Jung Kim ${ }^{1}$, Mi-Jin Lim², Jee-Young Han ${ }^{3}$, Kwang-Woo Lee ${ }^{3}$, \\ Jung-Joon Sung ${ }^{3}$, Choong Kun $\mathrm{Ha}^{1}$ and Seong Hye Choi ${ }^{1 *}$ \\ ${ }^{1}$ Department of Neurology, ${ }^{2}$ Division of Rheumatology, Department of Internal Medicine, Inha University Hospital, \\ Incheon 22332, ${ }^{3}$ Department of Neurology, Seoul National University Hospital, College of Medicine, Seoul 03080, Korea
}

A 25-year-old man presented with blurred vision and chronic headache. His brain MRI revealed bilateral frontal pachymeningeal enhancement with leptomeningeal enhancement. The patient had experienced recurrent oral ulcer and had anterior uveitis and papulopustules skin lesion. We diagnosed him with hypertrophic pachymeningitis (HP) associated with neuro-Behçet's disease (NBD). There have been few reports describing HP in patients with NBD. We report a case of NBD presenting as HP.

Key words: Behçet's disease, neuro-Behçet's disease, Hypertrophic pachymeningitis

\section{INTRODUCTION}

Behçet's disease (BD) is a multisystem recurrent inflammatory disorder that primarily affects young men. It is usually manifested as recurrent oral and genital ulcers, and skin and eye alterations. Other organs and the nervous system may be affected. The neurological complication of $\mathrm{BD}$, termed neuro-Behçet's disease (NBD), occurs in 5 30\% of patients with BD [1]. Parenchymal and non-parenchymal involvements are the most frequent types of NBD, while isolated meningeal involvement is rare. Several studies have reported cases with meningeal involvement, such as meningitis $[2,3]$. Hypertrophic pachymeningitis (HP) is a rare chronic inflammatory meningeal disorder associated with many conditions and characterized by a diffuse or localized thickening of the dura mater. There have been few reports describing HP in

Received June 2, 2015, Revised August 22, 2015,

Accepted September 8, 2015

${ }^{*}$ To whom correspondence should be addressed. TEL: 82-32-890-3668, FAX: 82-32-890-3097

e-mail:nrybn1230@gmail.com patients with NBD. Here, we report a case of NBD presenting as HP.

\section{CASE}

A 25-year-old man presented with chronic headache and a 10 day history of blurred vision. The headache was characterized by gradual onset, around the both frontal area occurring over the prior 3 months. The headache persisted all day, was pressing in nature and involved tightening with moderate intensity without nausea. There was no effect of the intensity in accordance with his position change. He did not take any medication for the headache. His visual acuity tests revealed 2/20 and 8/20 (right and left eye). Before the blurred vision, his visual acuities were 20/20 in both eyes. An ophthalmologist diagnosed him bilateral anterior uveitis. An oral examination showed several mucosal ulcerations with pain but no notable abscess or gingival disease (Fig. 1). He stated that he had experienced frequent oral ulcers over the past few years, but that they were not bothersome enough for him to seek medical care. Multiple papulopustules were present, especially on the trunk (Fig. 2A). Neither further focal neurological deficits
Copyright ( $\odot$ Experimental Neurobiology 2015. www.enjournal.org
This is an Open Access article distributed under the terms of the Creative Commons Attribution Non-Commercial License (http://creativecommons.org/licenses/by-nc/4.0) which permits unrestricted non-commercial use, distribution, and reproduction in any medium, provided the original work is properly cited. 
nor meningeal irritation signs including neck stiffness were detected. Gadolinium (Gd)-enhanced MRI revealed bilateral frontal pachymeningeal enhancement with leptomeningeal enhancement in the right frontal area (Fig. 3A, B). There were no evidences of optic nerve lesion or cerebral venous thrombosis. His past medical history was unremarkable and he was not taking any medication in a regular fashion. On examination, he appeared to be alert, comfortable and in no acute distress including febrile sense. His blood pressure, pulse, and temperature were 111/75 $\mathrm{mmHg}, 76$ beat $/ \mathrm{min}$, and $36.5^{\circ} \mathrm{C}$. Laboratory testing revealed a normal complete blood cell count. Viral studies in serum were negative for human immunodeficiency virus, cytomegalovirus (CMV), and Epstein-Barr virus. C-reactive protein (CRP) was significantly increased to $1.50 \mathrm{mg} / \mathrm{dL}$ (normal<0.3 $\mathrm{mg} / \mathrm{dL}$ ) and his erythrocyte sedimentation rate (ESR) was $35 \mathrm{~mm} / \mathrm{h}$. His venereal disease research laboratory test was negative and his angiotensin-converting enzyme level was normal. Tests for anti-nuclear antibodies, myeloperoxidase, and antineutrophil cytoplasmic antibodies were negative. An examination of his cerebrospinal fluid (CSF) demonstrated a normal opening

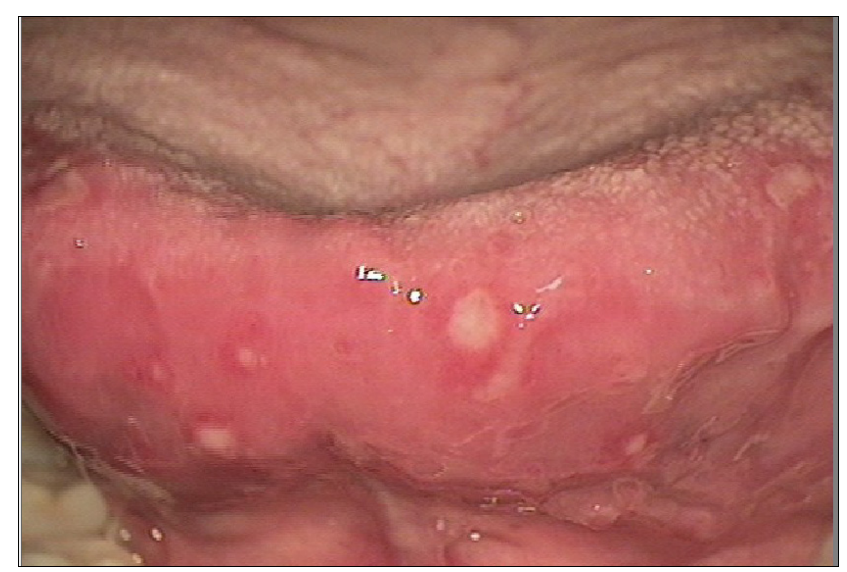

Fig. 1. Several mucosal ulcerations with pain is present on the anterior margin of the patient's tongue. pressure (13 $\mathrm{mmH}_{2} \mathrm{O}$ ), 17 leukocytes (90\% lymphocytes, 8\% monocytes, $2 \%$ neutrophils), an upper normal range protein level (55 mg/dL), and normal glucose levels. Adenosine deaminase in the CSF was normal and polymerase chain reactions for tuberculosis, herpes simplex virus, and CMV were negative. Screening for malignant cells was negative. We consulted a rheumatologist about the probability of BD for his anterior uveitis and recurrent oral ulcer. His skin pathergy test was positive (Fig. 2B). Human leukocyte antigen typing B51 was negative, and Schirmer's test results were normal. According to International Consensus Recommendation Diagnostic Criteria for Behcet's Disease, the rheumatologist diagnosed him definite NBD and non-parencymal NBD as depending on the location involved [4]. The patient received high dose intravenous methylprednisolone as a treatment for HP or NBD for 5 days, followed by oral prednisolone $(60 \mathrm{mg})$, and his headache and other symptoms gradually improved. Oral prednisolone $(60 \mathrm{mg})$ was continued without additional treatment. Two months later, his headache was gradually recovered. His visual acuity had improved to $16 / 20$ in both eyes. A follow-up brain MRI revealed nearly complete regression of the pachymeningeal enhancement (Fig. 3C, D). CRP and ESR were normalized $(0.46 \mathrm{mg} / \mathrm{dL}$ and $4 \mathrm{~mm} / \mathrm{hr})$. The CSF parameters improved to 5 leukocytes and a protein level of $39 \mathrm{mg} /$ dL. Prednisolone was tapered by $10 \mathrm{mg}$ every other day without other immunomodulatory agents. His oral ulcer has not recurred and papulopustules has been improvement. The patient remained symptom-free during an observation period of 12 months.

\section{DISCUSSION}

This patient presented with blurred vision and a non-specific chronic headache. The Gd-enhanced brain MRI showed a diffuse thickening of the pachymeninges and was consistent with HP. HP is an uncommon chronic inflammatory disorder characterized by a diffuse or localized thickening of the intracranial or spinal dura mater. Many conditions have been associated with this disease,

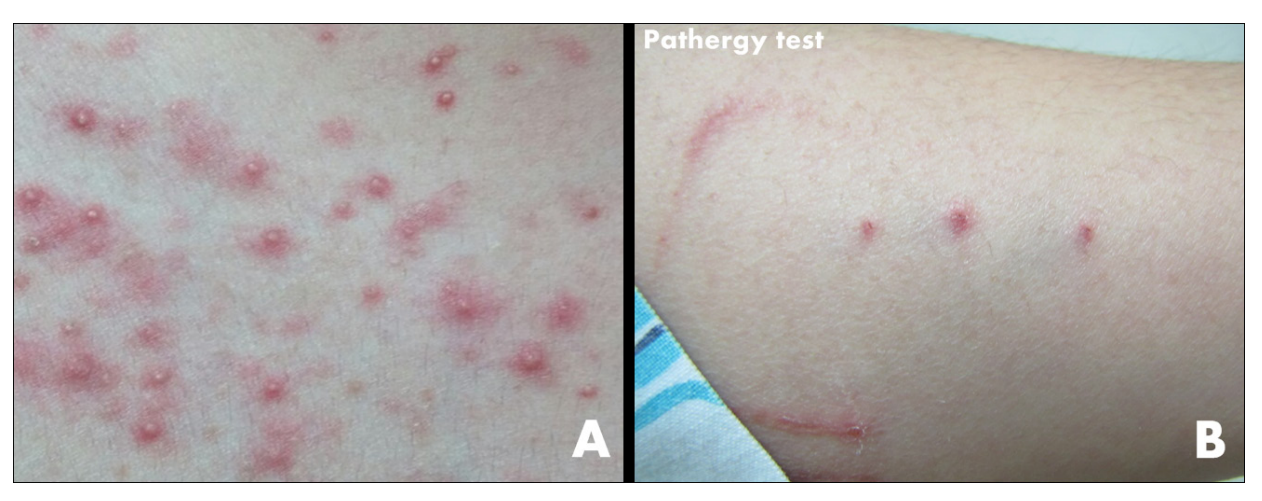

Fig. 2. (A) Pseudofolliculitis on the back, (B) Pathergy test showing positive response. 


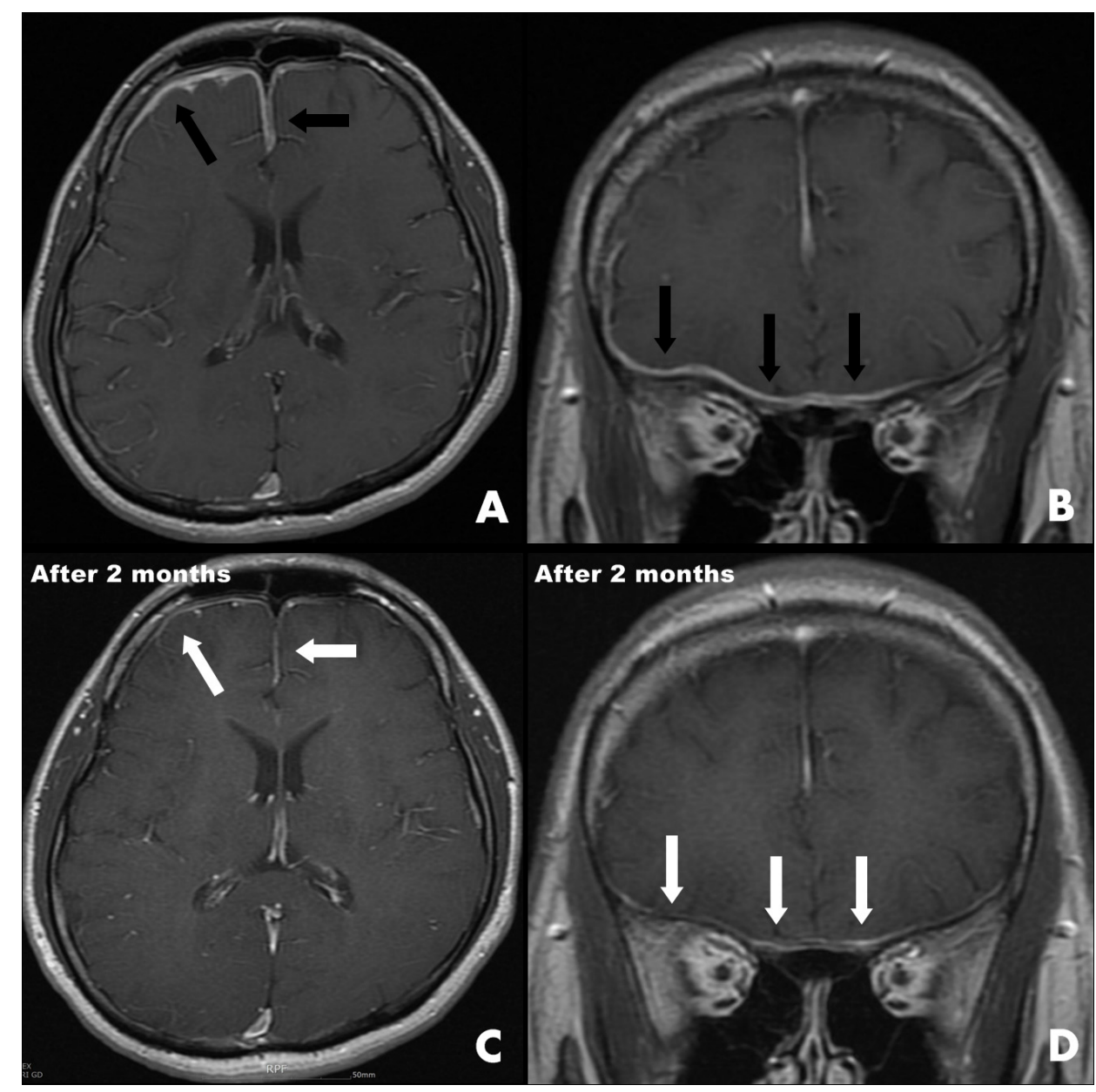

Fig. 3. MRI of the brain. (A, B) Axial and coronal T1 post-gadolinium images shows pachymeningeal enhancement (black arrows) at bilateral frontal especially at right frontal area. (C, D) In 2 months after the steroid therapy, followup MRI demonstrated nearly complete regression of the pachymeningeal enhancement (white arrows). including intracranial hypotension, inflammation (sarcoidosis), and neoplastic disorders (meningiomas, gliomas) $[5,6]$. The pathophysiology of HP is not well understood, although subacute or chronic meninigeal inflammation has been considered as potential causes. In this case, during the differential diagnosis, BD was revealed. BD is also a multisystem inflammatory disorder with a chronic course. Although the neurologic involvement (NBD) is less frequent than the other major presentations, it produces severe disabilities. NBD can involve both the central and peripheral nervous systems. It can be categorized into three main groups: parenchymal central nervous system (CNS) involvement, which includes brainstem, cerebral, spinal cord and optic neuropathy; nonparenchymal CNS involvement which includes cerebral venous thrombosis, intracranial hypertension syndrome, and acute meningeal syndrome; and peripheral nervous system involvement $[1,4]$. Although isolated meningeal presentation in NBD is quite rare, several cases have been reported as acute meningitis, and recurrent meningitis $[2,7]$. We suggest that if NBD affects the meninges, the meningeal chronic inflammation by NBD could be progressed to HP. There have been several reports of cases with other systemic inflammatory disorders such as Wegener's granulomatosis, rheumatoid arthritis, Sjogren's syndrome, mixed connective tissue disease [8-12]. To the best of our knowledge, there have been no previous reports of HP in a patient with BD.

Corticosteroids, mostly methylprednisolone pulse therapy followed by oral administration, were administered as the first choice for both HP and NBD. It is important to note that HP, in the absence of infection, responds well to treatment with corticosteroids. In a study conducted in Japan, a total of 94 cases received corticosteroids as initial immunotherapy, resulting in an 87.2\% improvement [13]. In 54 cases with an insufficient response to corticosteroids, immunosuppressants were added and $92.6 \%$ improved. On the other hand, when the evaluation fails to reveal a cause, idiopathic HP (IHP) should be considered. IHP frequently progresses if untreated, and although corticosteroid treatment improves the majority of patients, the benefit may be temporary and partial [14]. In order to avoid relapse, steroid doses were carefully tapered. If there is an insufficient or refractory response to steroids, clinicians should consider the addition of a second immonusuppresant, such as azathioprine or methotrexate. 
IgG4-related disease is a recently described inflammatory condition and is suggested to be a common cause in IHP [15]. Zachary, et al reported that $66 \%$ had been regarded previously as representing IHP were diagnosed as IgG4-related disease [16]. Therefore, the IgG4 test is necessary in IHP. Unfortunately, we did not measure his IgG4 titer.

The main symptoms and neurological findings of HP are headache, followed by cranial nerve symptoms. However, the headache associated with HP is non-specific and makes HP difficult to diagnose without performing Gd-enhanced MRI. Moreover, headache is a very common symptom in general and occurs not only in patients with $\mathrm{BD}$, but also in healthy people as well. This report indicates that NBD, similar to other systemic autoimmune disorders, may cause HP. Patients diagnosed with or suspected of having BD that complain of chronic headaches should undergo Gd-enhanced MRI to determine the possible presence of HP.

\section{CONFLICT OF INTEREST}

No potential conflict of interest relevant to this article was reported.

\section{REFERENCES}

1. Borhani Haghighi A, Pourmand R, Nikseresht AR (2005) Neuro-Behçet disease. A review. Neurologist 11:80-89.

2. Benjilali L, Harmouche H, El Bied S, Raffali J, Tazi Mezalek Z, Adnaoui M, Aouni M, Maaouni A (2008) Recurrent meningitis revealing a Behçet's disease. Rheumatol Int 29:9193.

3. Ural O, GençE, Demir NA, Balci M, GençBO (2009) NeuroBehçet's syndrome presenting with features mimicking acute tuberculous meningitis. Int J Infect Dis 13:e141-e144.

4. Kalra S, Silman A, Akman-Demir G, Bohlega S, BorhaniHaghighi A, Constantinescu CS, Houman H, Mahr A, Salvarani C, Sfikakis PP, Siva A, Al-Araji A (2014) Diagnosis and management of Neuro-Behçet' disease: international consensus recommendations. J Neurol 261:1662-1676.

5. Fishman RA, Dillon WP(1993) Dural enhancement and cerebral displacement secondary to intracranial hypotension. Neurology 43:609-611.

6. Ranoux D, Devaux B, Lamy C, Mear JY, Roux FX, Mas JL
(1992) Meningeal sarcoidosis, pseudo-meningioma, and pachymeningitis of the convexity. J Neurol Neurosurg Psychiatry 55:300-303.

7. Kara B, Somer A, Pişkin S, Aydinli N, Salman N, Yalçin I (2006) Neuro-Behçet syndrome presenting as acute meningeal syndrome. J Infect 52:e120-e123.

8. Nagashima T, Maguchi S, Terayama Y, Horimoto M, Nemoto M, Nunomura M, Mori M, Seki T, Matsukawa S, Itoh T, Nagashima K (2000) P-ANCA-positive Wegener's granulomatosis presenting with hypertrophic pachymeningitis and multiple cranial neuropathies: case report and review of literature. Neuropathology 20:23-30.

9. Ağildere AM, Tutar NU, Yücel E, Coşkun M, Benli S, Aydin P (1999) Pachymeningitis and optic neuritis in rheumatoid arthritis: MRI findings. Br J Radiol 72:404-407.

10. Yuh WT, Drew JM, Rizzo M, Ryals TJ, Sato Y, Bell WE (1990) Evaluation of pachymeningitis by contrast-enhanced MR imaging in a patient with rheumatoid disease. AJNR Am J Neuroradiol 11:1247-1248.

11. Li JY, Lai PH, Lam HC, Lu LY, Cheng HH, Lee JK, Lo YK (1999) Hypertrophic cranial pachymeningitis and lymphocytic hypophysitis in Sjögren's syndrome. Neurology 52:420-423.

12. Fujimoto M, Kira J, Murai H, Yoshimura T, Takizawa K, Goto I (1993) Hypertrophic cranial pachymeningitis associated with mixed connective tissue disease; a comparison with idiopathic and infectious pachymeningitis. Intern Med 32:510-512.

13. Yonekawa T, Murai H, Utsuki S, Matsushita T, Masaki K, Isobe N, Yamasaki R, Yoshida M, Kusunoki S, Sakata K, Fujii K, Kira J (2014) A nationwide survey of hypertrophic pachymeningitis in Japan. J Neurol Neurosurg Psychiatry 85:732-739.

14. Masson C, Hénin D, Hauw JJ, Rey A, Raverdy P, Masson M (1993) Cranial pachymeningitis of unknown origin: a study of seven cases. Neurology 43:1329-1334.

15. Chan SK, Cheuk W, Chan KT, Chan JK (2009) IgG4-related sclerosing pachymeningitis: a previously unrecognized form of central nervous system involvement in IgG4-related sclerosing disease. Am J Surg Pathol 33:1249-1252.

16. Wallace ZS, Carruthers MN, Khosroshahi A, Carruthers R, Shinagare S, Stemmer-Rachamimov A, Deshpande V, Stone JH (2013) IgG4-related disease and hypertrophic pachymeningitis. Medicine (Baltimore) 92:206-216. 